\title{
Computational Study of the Aerodynamic Performance of Subsonic Scarf Inlets
}

\author{
John M. Abbott ${ }^{*}$ \\ NASA John H. Glenn Research Center at Lewis Field, Brook Park, OH, 44135
}

\begin{abstract}
A computational study has been conducted to assess the aerodynamic performance of subsonic scarf inlets. The computations were performed using the WIND 3D Navier-Stokes CFD code. The objective of the study was to investigate the aerodynamic performance of scarf inlets wherein the circumferential extent, $\beta$, over which the transition from the extended lower lip to the non-extended lip was the primary variable. Other inlet design variables include inlet internal lip thickness and the axial length of the lower lip extension. Inlet performance is computed at takeoff, cruise and static conditions. The results indicate a fundamental change in the nature of the lip flow separation characteristics at takeoff conditions as $\beta$ is reduced from $180^{\circ}$ to $67.5^{\circ}$. The desire for separation-free performance at static and cruise conditions leads to restrictions on the range of inlet design variables.
\end{abstract}

\section{Introduction}

$\mathrm{E}$ NGINE inlets on most modern subsonic aircraft are only moderately three-dimensional (3D). The 3D features may take the form of canting of the inlet highlight plane (leading edge) and/or variable circumferential thickness. The idea of taking a step farther and making a subsonic inlet even more three dimensional in terms of inlet length, however, is something that is not seen too often. The concept is illustrated in figure 1. There are

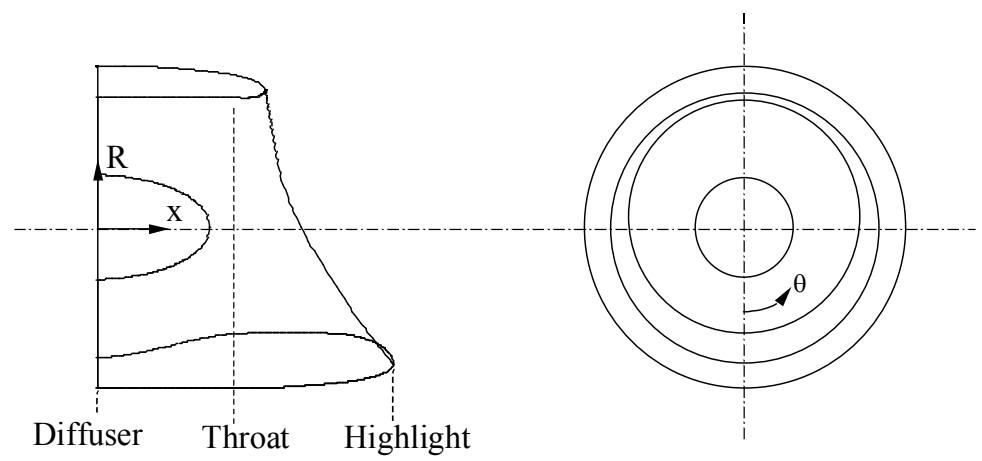

Exit Plane

Figure 1. Three-dimensional subsonic scarf inlet.

advantages to be gained from designing a subsonic inlet in such a manner. Perhaps the most significant advantage is the ability of such an inlet to affect the directivity of inlet radiated noise. Experimental research has shown that by extending the lower lip of the inlet to form a 3D "scarf" inlet, the inlet radiated noise will be redirected in such a way as to reduce the noise levels below the inlet (ref. 1). There is, of course, a corresponding increase in the noise levels above a scarf inlet, but the overall acoustic effect is positive since flyover noise radiating to the ground is what ultimately matters. A simple illustration of this characteristic is shown in figure 2(a).

One would also expect a scarf inlet to offer the advantage of a reduced tendency to ingest foreign objects from the ground during the takeoff and landing run. This reduced tendency is a result of the upward shift in the streamtube of incoming air to a scarf inlet as illustrated in figure $2 \mathrm{~b}$. And finally, wind tunnel experiments (ref.2)

${ }^{*}$ Senior Aerospace Engineer, NASA-Glenn, 21000 Brookpark Rd., M.S. 86-7, Brook Park, OH 44135 
have shown that for a given lip thickness, a scarf inlet is capable of operating at a higher angle-of-attack than an axisymmetric inlet while maintaining attached internal flow. This characteristic is illustrated in figure $2 \mathrm{c}$ and is again attributed to the upward shift of the capture streamtube which has the net effect of reducing the local angle-ofattack on the critical lower lip of the inlet for a given overall angle-of-attack. This characteristic then has a potential system payoff for reducing weight since extending the lower lip to form a scarf inlet, may permit a thinner lip design in order to meet a given maximum angle-of-attack requirement.

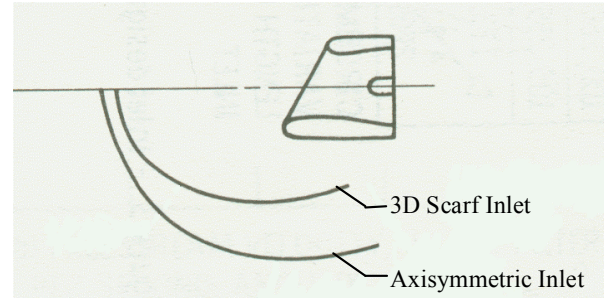

(a) Reduced noise levels below scarf inlet. (Lines of constant sound pressure level.)

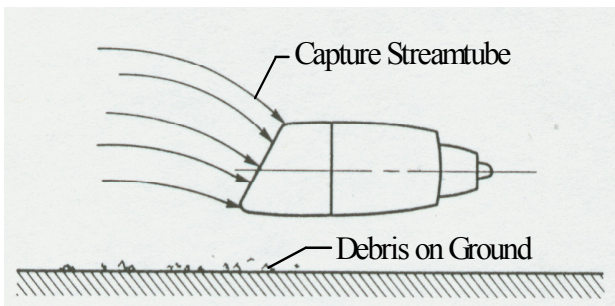

(b) Reduced tendency to ingest foreign objects.

Axisymmetric Inlet

3D Scarf Inlet
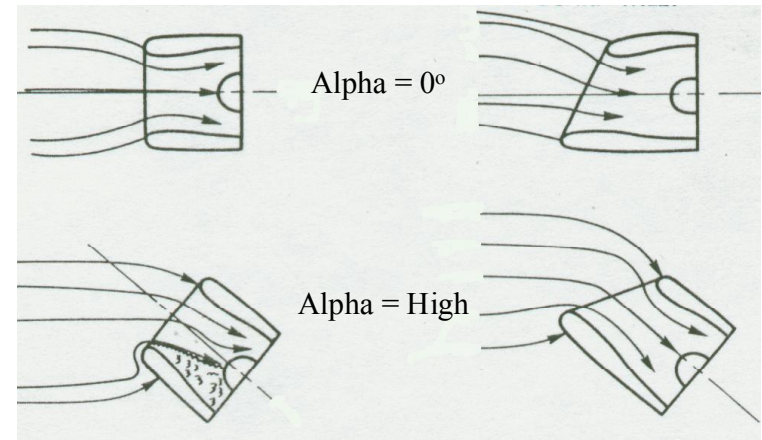

(c) Increased angle-of-attack capability for scarf inlet.

Figure 2. Subsonic scarf inlet performance advantages.

There are, of course, potential problems associated with a scarf inlet design. For one thing, the upward shift of the incoming streamtube cited as an advantage in the previous paragraph, can lead to problems at other operating conditions. In particular, at static or very low speed conditions, the upper lip of a scarf inlet sees a much higher surface velocity than an axisymmetric design and for some amount of lower lip extension, the flow will separate from the upper lip. Also, at cruise conditions, the spillage flow will be asymmetric with more flow spilling over the upper external lip than the lower. This characteristic can lead to added cruise drag (and changes in inlet lift) if the external lip of the inlet is not designed properly. Both of these potential problems are illustrated in figures $3 a$ and $b$.

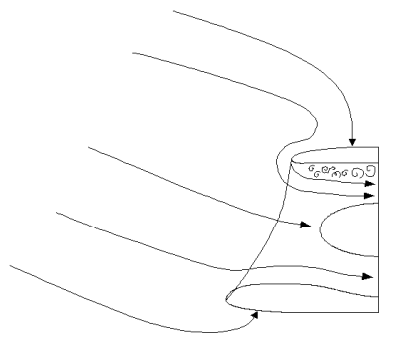

(a) Upper lip internal flow separation at static conditions.

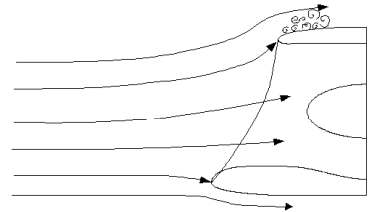

(b) Upper lip external flow separation at cruise conditions.

Figure 3. Subsonic scarf inlet performance challenges. 
In view of the potential advantages and disadvantages discussed above for subsonic scarf inlets, a computational study to investigate the aerodynamic performance of scarf inlets was initiated several years ago and preliminary results were presented in reference 3. The objective of this paper is to present additional results of this study designed to investigate the aerodynamic performance of scarf inlets wherein the circumferential extent over which the transition from the extended lower lip to the nonextended lip is the main variable. This current investigation was motivated by the desire to keep scarf inlet surface area and weight (volume) to a minimum while meeting the imposed aerodynamic design requirements. This objective would be best served by transitioning from the extended lower lip to the shorter lip length in as small a circumferential angle as possible. Hence the question for this study becomes: How is scarf inlet performance affected by the circumferential extent of the lip extension?

\section{Computational Method}

The inlet geometries for the study were developed using a Three Dimensional Subsonic Inlet Geometry Generator (3D-SIGG). 3D-SIGG is a Microsoft Excel spreadsheet in which the basic inlet geometry design parameters are specified and all other design parameters are calculated. 3D-SIGG also develops the surface coordinates and computes the inlet volume and surface area. The coordinates generated by 3D-SIGG are then passed on to the Subsonic Inlet Grid Generator (SUBING). SUBING generates the computational grid which is used in the three-dimensional Navier-Stokes CFD code, WIND. A sample computational grid, generated by SUBING, is shown in figure 4.

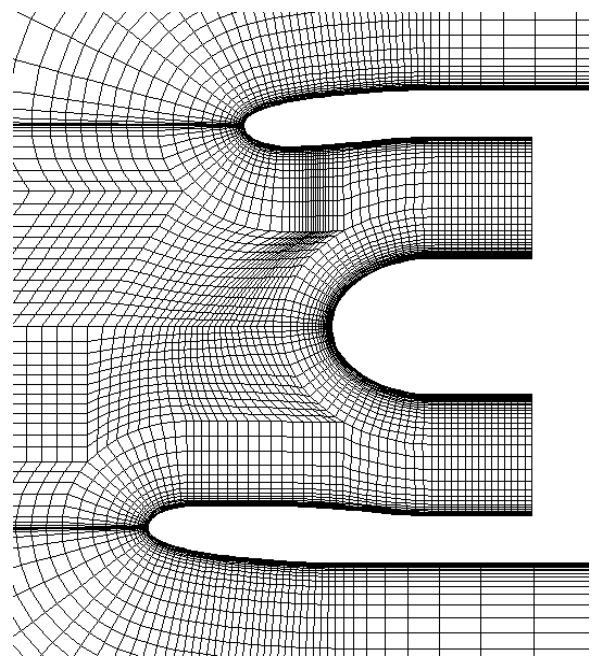

Figure 4. Sample computational grid generated by SUBING.

The flow computations were performed using the WIND code (refs 4 and 5). WIND is being developed by the NPARC Alliance (National Program for Applications-oriented Research in CFD), which is a partnership between the NASA Glenn Research Center, the Air Force's Arnold Engineering Development Center, and the Boeing Company. WIND solves the time-dependent, Reynolds-averaged Navier-Stokes equations for turbulent, compressible flows using a cell-vertex, finite-volume, time-marching approach on multi-zone, structured grids. Spatial accuracy is nominally second-order using the Roe flux-difference splitting upwind formulation. Steady flows are simulated through an iterative process using local time stepping. Turbulence is modeled using one- or twoequation eddy viscosity models. The Spalart-Allmaras and SST models are the most-often-used models. WIND is capable of solving for flows of speeds ranging from low subsonic to hypersonic.

\section{Validation}

To develop confidence in the ability of the WIND code to accurately predict subsonic scarf inlet aerodynamic performance, it is necessary to validate the computational results by comparison with experimental data. The results of such a validation study were presented in reference 3 . The reference also gives more details of how the computations were performed. 


\section{A Family of Scarf Inlet Designs}

For the study presented in this paper, a series of scarf inlet designs was developed wherein the primary variable of interest was the circumferential extent, $\beta$, over which the extended lip lower lip is formed. In the study, $\beta$ takes on 5 discrete values: $180,135,112.5,90$ and 67.5 degrees. Scarf inlets at the two extremes having $\beta$ 's of 180 and 67.5 degrees are shown in figure 5. Both inlets have the same amount of axial extension of the lower lip.

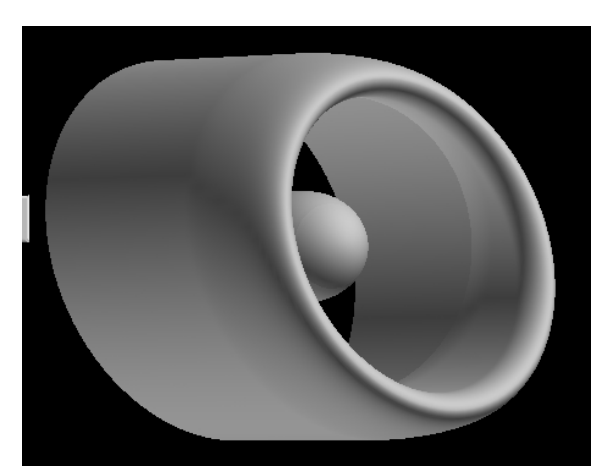

(a) $\beta=180^{\circ}$

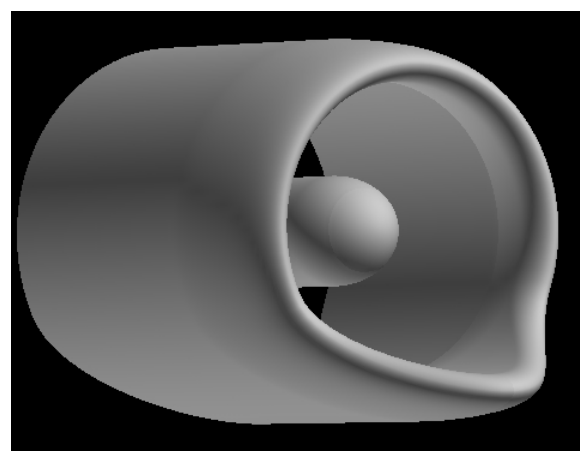

(b) $\beta=67.5^{\circ}$

Figure 5. Scarf inlet designs.

Now, for each of these $\beta$ 's, a whole "family" of inlet designs was developed wherein the inlet lip contraction ratio and the length of the lower lip extension were varied. In total, at each of the 5 values of $\beta, 3$ different contraction ratios and 9 different lower lip extension lengths were considered making for a total of 135 different scarf inlet configurations that were analyzed. In developing this family of inlet designs a number of groundrules were set and are summarized as follows (refer to figure 6 for design variable definitions):

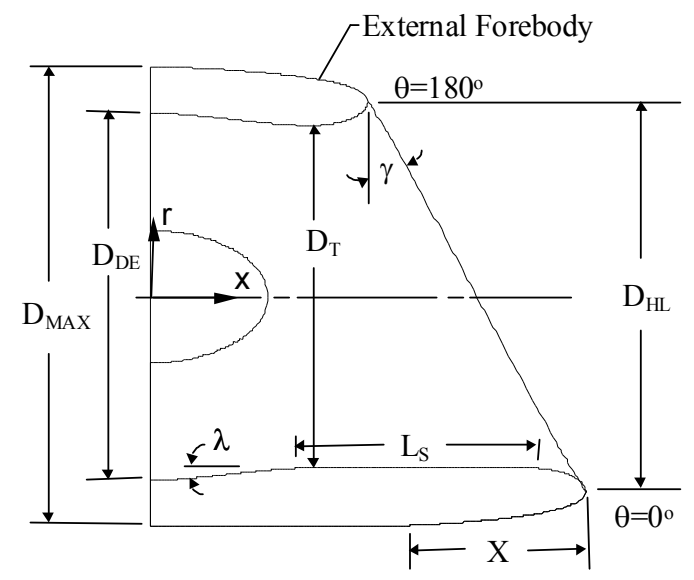

Figure 6. Scarf inlet nomenclature $\left(\beta=180^{\circ}\right)$

1. All inlets in the family have the same cruise design conditions: $\mathrm{M}_{0}=0.8$, and the drag divergence Mach number of the external forebody, $\mathrm{M}_{\mathrm{DD}}$, is 0.84 . 
2. At all freestream operating conditions $\left(\mathrm{M}_{\mathrm{o}}\right.$ and $\left.\alpha\right)$, the inlet mass flow is constant corresponding to an inlet diffuser exit Mach number, $\mathrm{M}_{\mathrm{DE}}$, of 0.6.

3. The inlet diffuser exit diameter is fixed at 12 inches and the inlet thickness at the diffuser exit plane is constant at 1.5 inches resulting in a $\mathrm{D}_{\mathrm{MAX}} / \mathrm{D}_{\mathrm{DE}}$ of 1.25 .

4. Inlet contraction ratio, $C R$, the ratio of the inlet highlight area to throat area, $\left(\mathrm{D}_{\mathrm{HL}}\right)^{2} /\left(\mathrm{D}_{\mathrm{T}}\right)^{2}$, takes on three different values within the family of inlets. $\mathrm{CR}=1.2,1.25$. and 1.3 .

5. The windward lip of the inlet is extended to form the scarf geometries. The extension is defined by the length of the windward lip extension divided by the inlet diffuser exit radius, $L_{S} / R_{D E}$. Specific values considered are 0 (axisymmetric design), $0.125,0.25,0.375,0.5,0.625,0.75,0.875$, and 1.0 .

6. The inlet lip extension varies with circumferential position, $\theta$, according to the cubic equation,

$$
\mathrm{L}_{\mathrm{S}}=\mathrm{L}_{\mathrm{S}-0}{ }^{0}\left[2(\theta / \beta)^{3}-3(\theta / \beta)^{2}+1\right]
$$

as $\theta$ varies from $0^{\circ}$ (windward) to $\beta$, where $\beta$ is the circumferential angle where the extension ends and $\mathrm{L}_{\mathrm{s}-0}{ }^{\circ}$ is the maximum length of the extension at $\theta=0^{\circ}$.

7. The value of $\beta$ takes on 5 discrete values: $180,135,112.5,90$, and 67.5 degrees.

8. The length of the inlet diffuser is designed to be as short as possible within the following constraints: (a) The maximum local diffuser wall angle, $\lambda_{\mathrm{MAX}}$, is less than or equal to $8.0^{\circ}$; (b) The external forebody length, $\mathrm{X}$, must be retained in full; and (c) The centerbody must not penetrate the inlet throat plane.

Applying these groundrules results in the family of 27 inlet designs for a given value of $\beta$ of which 15 are shown in figure 7 for $\beta=180^{\circ}$. Those missing correspond to $L_{S} / R_{D E}=0.125,0.375,0.625$, and 0.875 . Because the inlet

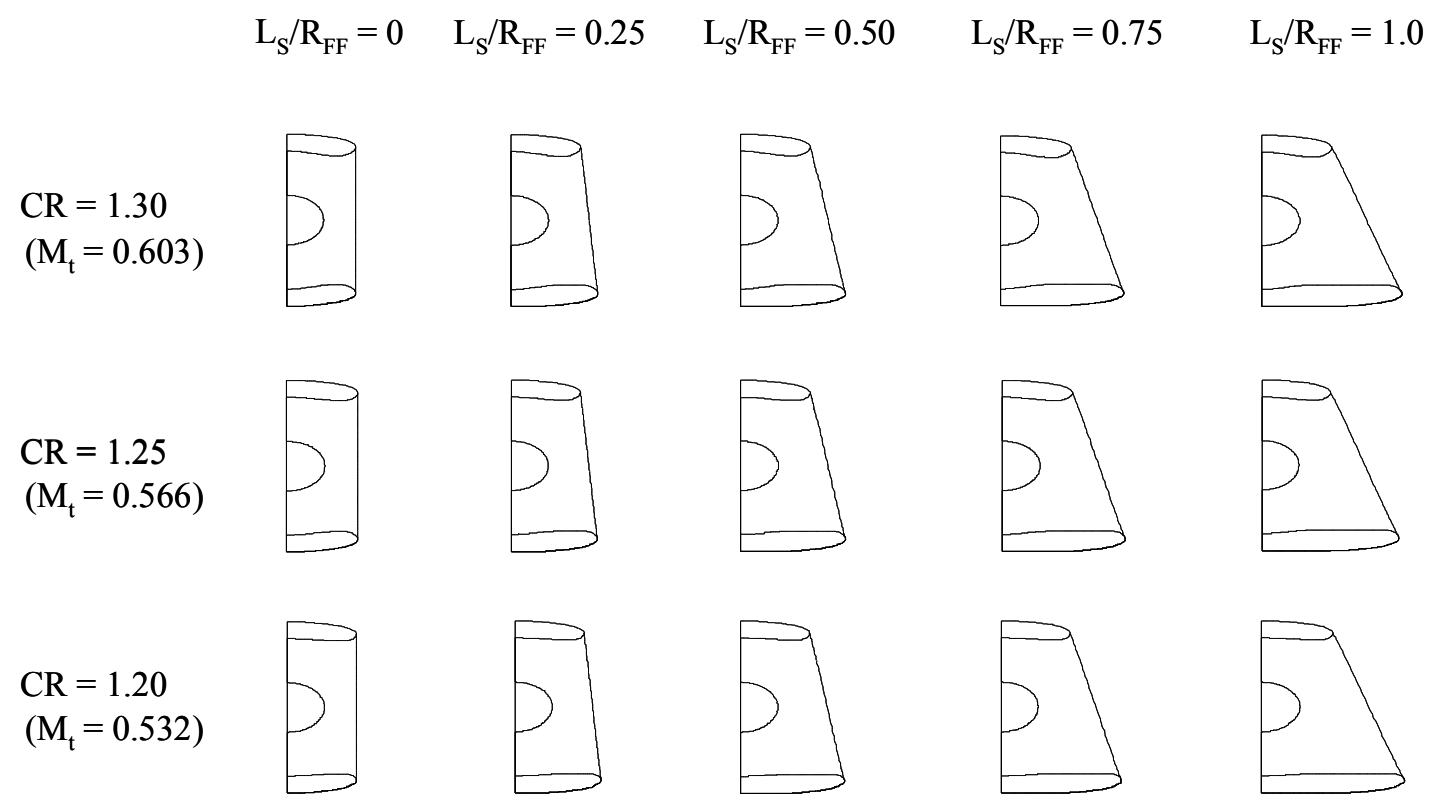

Figure 7. Family of subsonic scarf inlet designs for $\beta=180^{\circ}$ (15 of 27 shown). 
maximum diameter is fixed and the constant cruise design results in a constant ratio of $\mathrm{D}_{\mathrm{HL}} / \mathrm{D}_{\mathrm{MAX}}$, the inlet throat diameter, $\mathrm{D}_{\mathrm{T}}$, and hence the inlet throat Mach number must vary as inlet contraction ratio, CR, is changed. Specifically, for the three contraction ratios being considered:

$$
\begin{array}{ll}
\underline{\mathrm{CR}} & \underline{\mathrm{Mt}} \\
1.20 & 0.532 \\
1.25 & 0.566 \\
1.30 & 0.603
\end{array}
$$

Although the three contraction ratio designs must have different design throat Mach numbers per the groundrules, the throat Mach number values themselves are fairly close to one another and well within the standard design range.

It should be pointed out, that by changing some of the groundrules, a different family of scarf inlet designs would be formed that would be equally valid and worthy of investigation

\section{A. Determining Separation Angle-of-attack}

In order to assess and compare the aerodynamic performance of this large number of scarf inlet configurations, computations were first performed with the WIND code at typical takeoff conditions. As stated in the groundrules, the inlet mass flow was set to a value corresponding to an inlet diffuser exit Mach number of 0.6. A takeoff freestream Mach number of 0.25 was then assumed and computations were done for each of the 135 geometries. The primary goal of the calculations was to determine the angle-of-attack where the internal flow separated from the windward lip, $\alpha_{\text {SEP }}$ This was accomplished by computing the flowfield at progressively higher angles-of-attack while examining the axial distribution of surface skin friction coefficient, $\mathrm{C}_{\mathrm{f}}$, At the angle-of-attack where $\mathrm{C}_{\mathrm{f}}$ became zero at some location on the inlet surface, that angle was defined as $\alpha_{\mathrm{SEP}}$.

It should be noted that at all angles-of-attack up to $\alpha_{\mathrm{SEP}}$, the inlet total pressure recovery was high and the total pressure distortion was low. At takeoff conditions, only after the angle-of-attack exceeds $\alpha_{\text {SEP }}$, does the overall inlet performance begin to suffer.

After having determined $\alpha_{\text {SEP }}$ for all 27 geometries at a given value of $\beta$, figure 8 could be constructed. In this

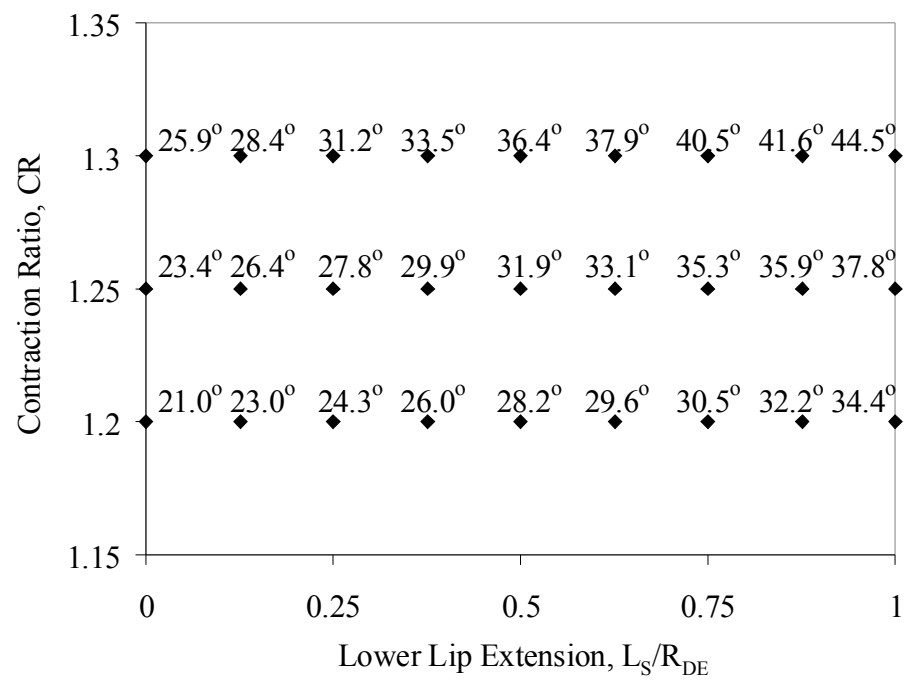

Figure 8. Separation angle-of-attack at takeoff conditions. $\beta=180^{\circ}$; $\mathrm{M}_{\mathbf{0}}, 0.25 ; \mathrm{M}_{\mathrm{DE}}, \mathbf{0 . 6 0}$. 
case the figure is shown for $\beta=180^{\circ}$ (see figure 5(a)). The figure is a plot of inlet contraction ratio, $\mathrm{CR}$, versus the extent of lower lip extension, $\mathrm{L}_{\mathrm{S}} / \mathrm{R}_{\mathrm{DE}}$. A solid symbol is placed on the figure at the proper location for each of the 27 geometries and $\alpha_{\text {SEP }}$ for that geometry is noted next to the symbol. Note that there is a one to one connection with the symbols on figure 8 and the geometries in figure 7. The figure indicates how for a given contraction ratio, the value of $\alpha_{\text {SEP }}$ increases as the lower lip of the inlet is extended. For example at a contraction ratio of 1.25, modifying an axisymmetric inlet by extending its lower lip by $50 \%$ of the diffuser exit radius $\left(\mathrm{L}_{\mathrm{S}} / \mathrm{R}_{\mathrm{DE}}=0.5\right)$, increases $\alpha_{\text {SEP }}$ from $23.4^{\circ}$ to $31.9^{\circ}$.

From figure 8 , figure 9 was constructed in which lines of constant $\alpha_{\text {SEP }}$ have been drawn using a linear interpolation between the points on figure 8 . Also added to figure 9 are a second parameter along the $\mathrm{x}$-axis, $\gamma$, and dashed lines of inlet volume as determined by 3D-SIGG.

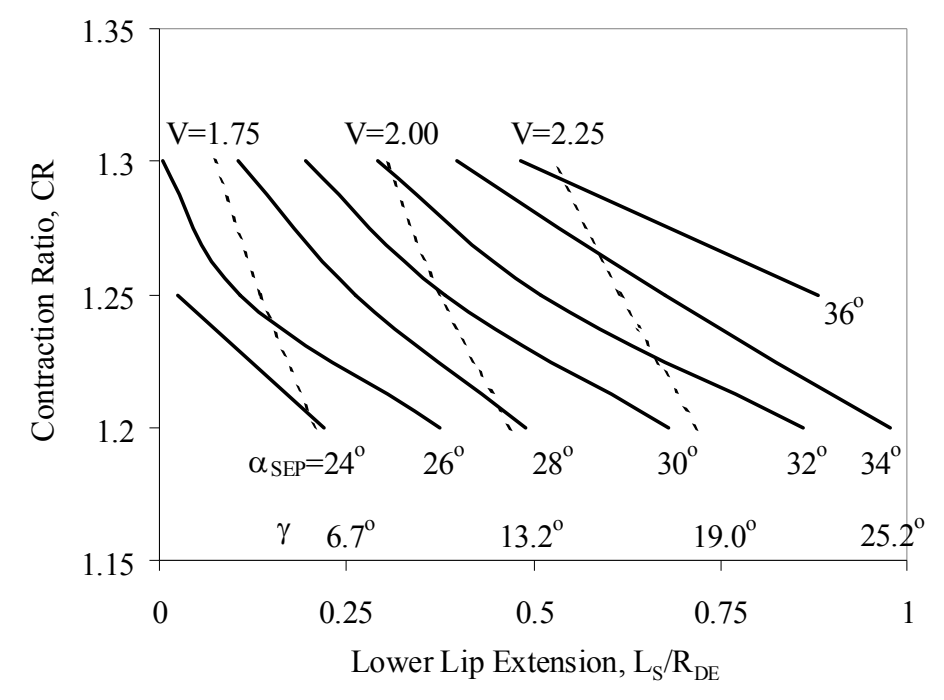

Figure 9. Separation angle-of-attack and inlet volume at takeoff conditions. $M_{0}, 0.25 ; M_{D E}, 0.60$.

The parameter $\gamma$ is defined as the scarf angle and is defined in figure 6. The volume numbers are nondimensional and should only be considered in a relative context. These lines of constant volume assist in determining what is happening relative to inlet volume, and hence weight, as one moves about the figure to various levels of lower lip extension and contraction ratio. As an example, if it was required that a subsonic inlet operate up to an angle-of-attack of $26^{\circ}$ at takeoff, then an axisymmetric inlet with a contraction ratio of 1.3 could be selected or an inlet with a contraction ratio of 1.2 and a lower lip extension of $\mathrm{L}_{\mathrm{S}} / \mathrm{R}_{\mathrm{DE}}=0.375$ could also be selected. And in moving from the axisymmetric inlet to this extended lower lip inlet, the volume would increase from about 1.67 to 1.91 , or about $14 \%$. The question then becomes whether or not the advantages associated with the extended lower lip (see figure 2(a) and (b)) offset the added volume.

\section{B. Static and Cruise Performance}

Now, as was pointed out in figure 3, there are issues relative to static and cruise performance that must be considered as part of this subsonic scarf inlet evaluation. First, at static conditions, for some amount of lower lip extension, the internal flow will separate from the upper lip of the inlet due to the upward shift of the capture streamtube (figure 3a). To assess this aspect of performance, calculations were performed for each of the geometries at static conditions and once again surface skin fiction coefficient, $\mathrm{C}_{\mathrm{f}}$, was monitored on the internal surface of the "windward" side $\left(\theta=180^{\circ}\right)$. And again, $C_{\mathrm{f}}=0$ was used as the criterion for separation. Results of these calculations are shown in figure 10, which is simply figure 9 with this "static separation bound" added. To the left of the bound the internal flow is attached at static conditions, to the right it is separated. Note that as would be 


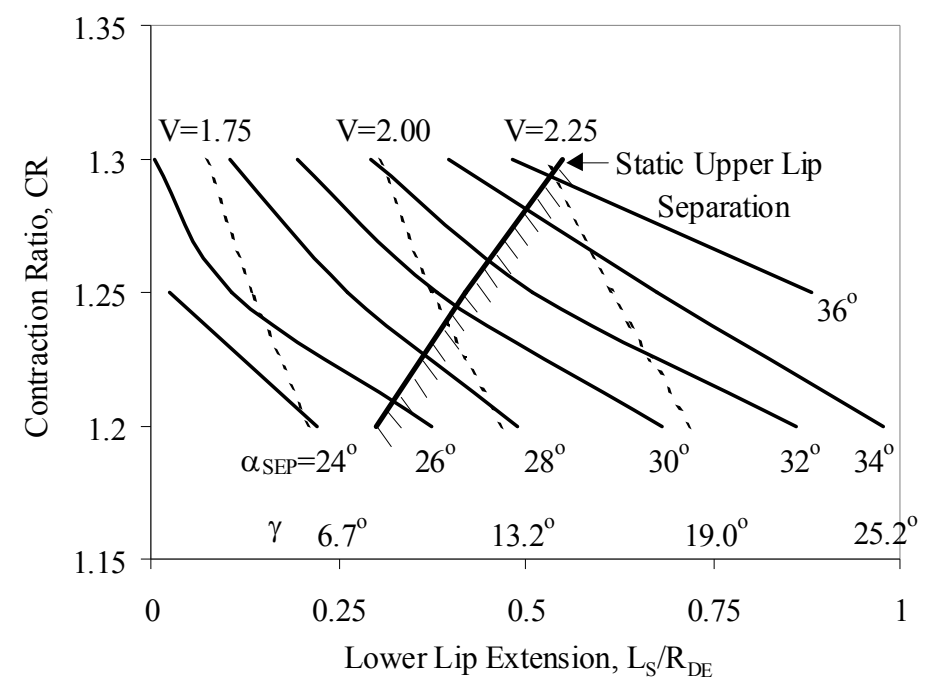

Figure 10. Impact of upper lip flow internal separation at static conditions. $\beta=\mathbf{1 8 0}^{\circ}$.

expected, as contraction ratio is increased, the amount of lower lip extension that can be accommodated while avoiding upper lip flow separation, increases. Also note that in the example discussed previously ( the angle-ofattack of $26^{\circ}$ case), at the contraction ratio of 1.2 point, the flow would be separated at static conditions and perhaps this would then be an inlet design point to be avoided.

Continuing to build on figure 10, consideration of the cruise condition adds another operating limit. At cruise, due to the asymmetric spillage flow characteristics of an extended lower lip scarf inlet, more flow will naturally spill over the upper external lip (external forebody) than over the lower external lip. And at some amount of extended lower lip, the external flow will separate from the lip at the $\theta=180^{\circ}$ position (figure $3 \mathrm{~b}$ ). Calculations were performed for the family of geometries at a cruise Mach number, $\mathrm{M}_{\mathrm{o}}$, of 0.8 and an angle-of-attack of $0^{\circ}$ to determine this external flow separation limit. These results are presented in figure 11 and now provide a subsonic scarf inlet design chart for the family of inlets developed according to the groundrules described previously.

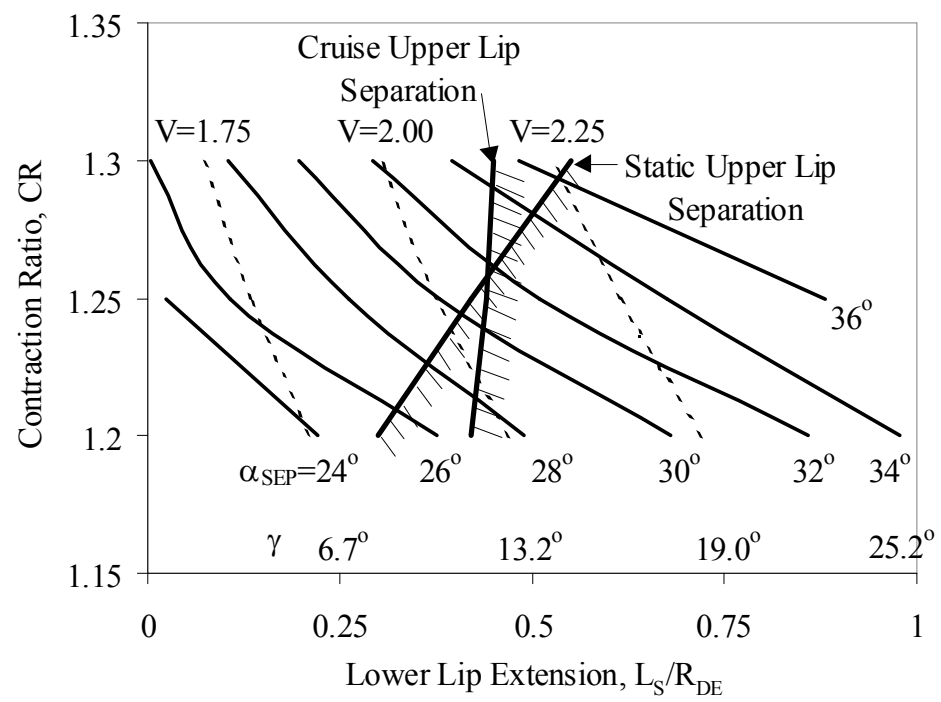

Figure 11. Impact of upper lip flow external separation at cruise conditions. 


\section{Final Comments}

A few final comments should be made about figure 11. First, these results are "ground-rule specific" - change the inlet design ground-rules and all the curves on figure 11 change. Second, additional scarf inlet design modifications could lead to an expansion of the acceptable design space located to the left of the static and cruise separation bounds. For example, local tailoring of both the internal and external upper lip design could well push those bounds to the right with only a small additional increase in inlet volume and weight. Third, there are other operating conditions, that have not yet been investigated, that will impose additional operating limits on figure 11. These include operation in a crosswind and during engine-out climb.

\section{Effect of $\beta$}

Now that the groundwork has been set for the $\beta=180^{\circ}$ configuration, the discussion will move on to examining the effect of decreasing $\beta$ on scarf inlet aerodynamic performance. As stated in the "Introduction": This current investigation was motivated by the desire to keep scarf inlet surface area and weight (volume) to a minimum while meeting the imposed aerodynamic design requirements. This objective would be best served by transitioning from the extended lower lip to the shorter lip length in as small a circumferential angle as possible. Hence the question for this study becomes: How is scarf inlet performance affected by the circumferential extent of the lip extension?

Figure 12 shows results for the $\beta=135^{\circ}$ family of inlet designs. The results are shown in the exact same format as those for the $\beta=180^{\circ}$ family in figure 11 .

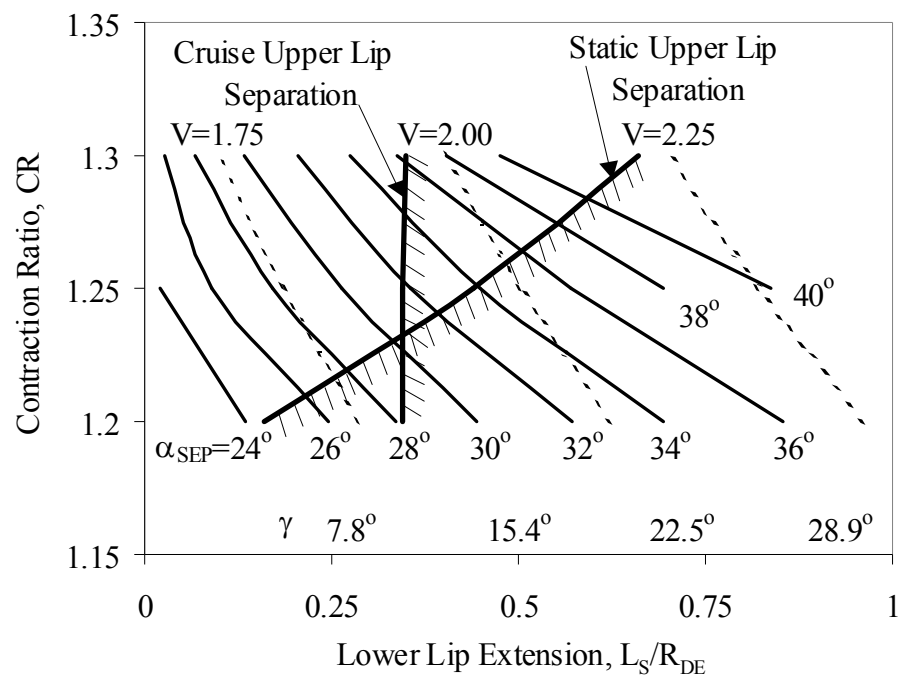

Figure 12. Performance of subsonic scarf inlets with $\beta=135^{\circ} . M_{0}, 0.25 ; M_{D E}, 0.60$.

Note first of all that for this second family, at a given contraction ratio and lower lip extension, the separation angle-of-attack, $\alpha_{\mathrm{SEP}}$, is higher. This is not too surprising in that for low values of $\theta$, the lower lip is actually extended more forward for the $\beta=135^{\circ}$ case than for the $\beta=180^{\circ}$. Or, in other words, the value of $\gamma$ is actually higher for a given lower lip extension for the $135^{\circ}$ case. This is reflected in the $\gamma$ scale shown along the x-axis when compared to the same scale in figure 11. What this means is that the capture streamtube is actually shifted further upward for the $135^{\circ}$ case, at least in the lower lip region of the inlet. The second point to be made from the figure is that the separation bound at cruise has shifted to the left from where it was for the $180^{\circ}$ case. This suggests that the asymmetric spillage (see figure 3(b)) is greater for this family of designs which is consistent with the upward shifted capture steamtube. The static separation bound for the $135^{\circ}$ case has shifted a bit to the left at the lowest inlet contraction ratio, but has shifted significantly to the right for most of the contraction ratio range. This result suggests that a larger extent of the upper portion of the inlet lip is sharing the flow turning and therefore a greater amount of lower lip extension can be tolerated before the upper portion of the lip separates. In fact, a more detailed analysis of the results shows that at static conditions, when the flow does separate, it actually separates at 
circumferential positions of around $135^{\circ}$, rather than at the $180^{\circ}$ angle. And finally, as would be expected, the dashed lines of constant volume have shifted to reflect the lower inlet volume for a given design point attributed to the reduction in transition angle from $180^{\circ}$ to $135^{\circ}$.

Figure 13 shows results for the $\beta=112.5^{\circ}$ case. This additional decrease in $\beta$ has again resulted in a higher separation angle-of-attack for a given contraction ratio and lower lip extension, however for the larger values of lower lip extension, the lines of constant separation angle-of-attack "turn-up" for the higher angles-of-attack. This suggests a change in the flow separations characteristics as $\beta$ has been decreased to $112.5^{\circ}$. It should be noted, however, that this change occurs far beyond the cruise and static upper lip flow separation limits so it is of no practical consequence to the range of acceptable scarf inlet design parameters. And finally, for $\beta=112.5^{\circ}$ the cruise and static separation bounds have shifted in about the same manner that they did in going from $\beta=180^{\circ}$ to $135^{\circ}$, although the magnitude of the shift is not quite as great because of the decrease in $\beta$ by only $22.5^{\circ}$ rather than $45^{\circ}$.

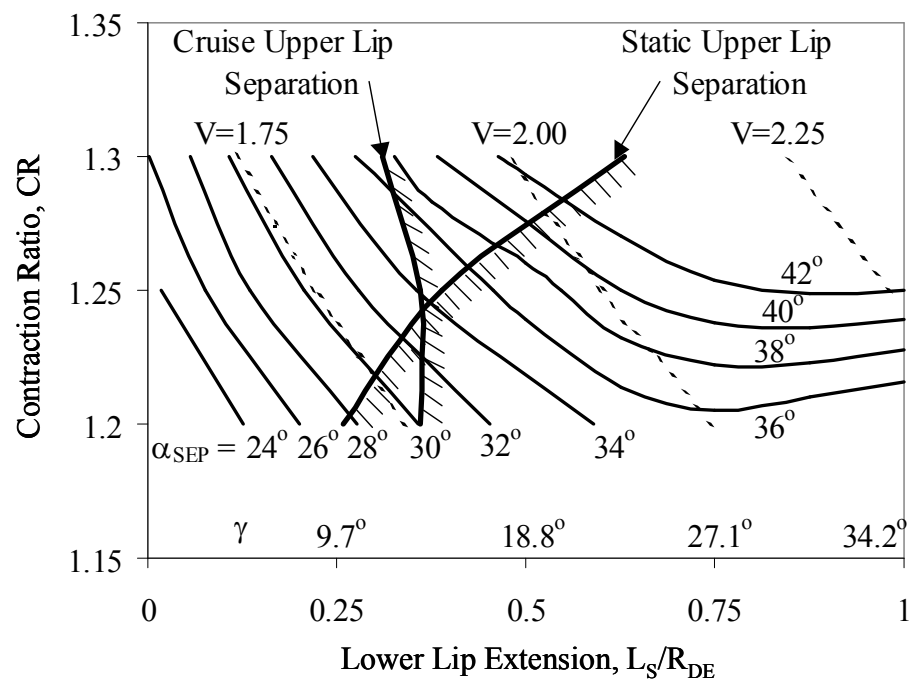

Figure 13. Performance of subsonic scarf inlets with $\beta=112.5^{\circ} ; M_{0}, 0.25 ; M_{D E}, 0.60$.

The effect of further reducing $\beta$ to $90^{\circ}$ is shown in figure 14 . The shift in the lines of constant separation angleof-attack and the static and cruise upper lip separation bounds is once again in the same direction and now the up-

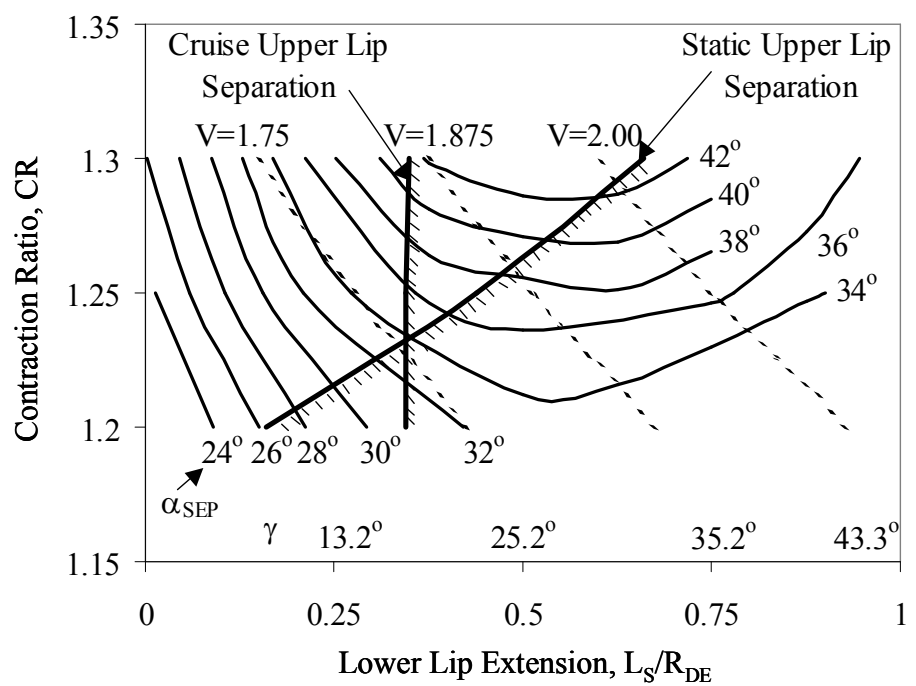

Figure 14. Performance of subsonic scarf inlets with $\beta=90^{\circ} ; M_{0}, 0.25 ; M_{D E}, 0.60$. 
turn at high values of lower lip extension and angle-of-attack is even more pronounced. However, as before, the upturn is not a factor within the range of permissible design variables, i.e. to the left of the cruise and static separation limits.

And finally figure 15 shows results for the $\beta=67.5^{\circ}$ case. The figure shows the same trends in the constant separation angle-of-attack lines and the cruise and static upper lip separation lines. It also shows a continued increase in the extent of the turn up behavior of the separation angle-of-attack lines. This behavior has now extended into the range of the allowable design space, i.e., to the left of the cruise and static bounds.

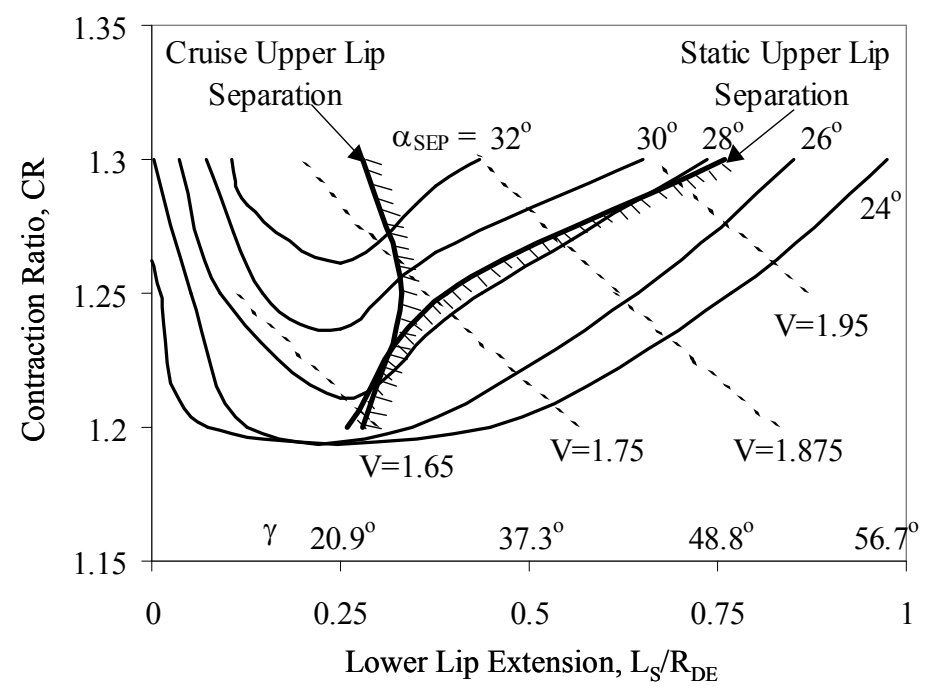

Figure 15. Performance of subsonic scarf inlets with $\beta=67.5^{\circ} ; M_{0}, 0.25 ; M_{D E}, 0.60$.

A more detailed look at scarf inlet performance is now in order to understand the underlying reasons for this change in scarf inlet behavior as $\beta$ is decreased. Figure 16 shows values of surface skin-friction coefficient for the $\beta$ $=67.5^{\circ}$ case. All results in the figure are for an inlet contraction ratio of 1.25. Figure 16(a) shows results at a lower lip extension $\left(\mathrm{L}_{\mathrm{S}} / \mathrm{R}_{\mathrm{DE}}\right)$ of 0.125 , figure 16 (b) for 0.250 and figure $16(\mathrm{c})$ for 0.625 . Each individual figure shows results at an angle-of-attack just beyond that for internal flow separation. Those angles are $29.9^{\circ}, 31^{\circ}$, and $27^{\circ}$ as $\mathrm{L}_{\mathrm{S}} / \mathrm{R}_{\mathrm{DE}}$ increased from 0.125 to 0.250 to 0.625 . As figure 16(a) indicates, flow separation is initiated inside the lower lip circumferential position when the lower lip is least extended. This can be seen from the small "patch" of green that appears on the inlet surface representing a skin friction coefficient of zero. As the lower lip is extended to $\mathrm{L}_{\mathrm{S}} / \mathrm{R}_{\mathrm{DE}}$ of 0.25 and then 0.625 (figures 16(b) and (c)) the flow separation region on the lip migrates up toward the "corner" of the inlet side profile, i.e. the lower lip is no longer the critical flow separation location. This explains the significant change in the results shown in figures 12 through 15 as $\beta$ is reduced. In essence, once the corner of the side profile becomes the circumferential location for internal flow separation, further increases in lower lip extension, make that corner sharper, i.e. $\gamma$ increases, and the separation angle-of -attack then begins to decrease.

This same behavior was observed experimentally and was reported in reference 2 . In those experiments two scarf inlets were tested, one with $\beta=180^{\circ}$ and one with $\beta=113.6^{\circ}$. Total pressure profiles at the inlet diffuser exit plane shown in that reference indicate that for the $\beta=113.6^{\circ}$ case, the flow has separated in the "corner" region of the scarf inlet side profile. No such behavior is observed for the $\beta=180^{\circ}$ case. 


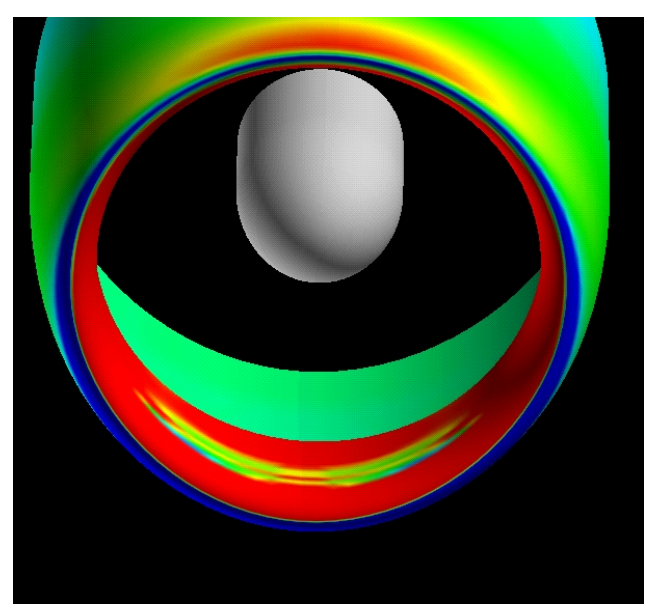

(a) $\mathrm{L}_{\mathrm{S}} / \mathrm{R}_{\mathrm{FF}}=0.125 ; \alpha=29.9^{\circ}$

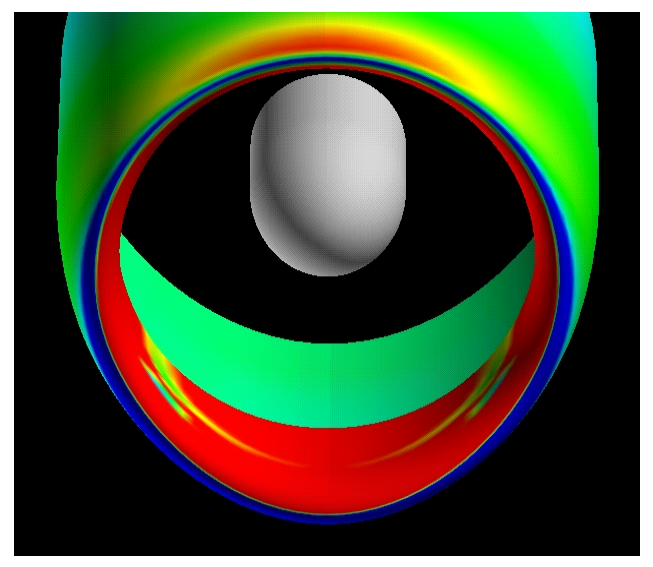

(b) $\mathrm{L}_{\mathrm{S}} / \mathrm{R}_{\mathrm{FF}}=0.250 ; \alpha=31.0^{\circ}$

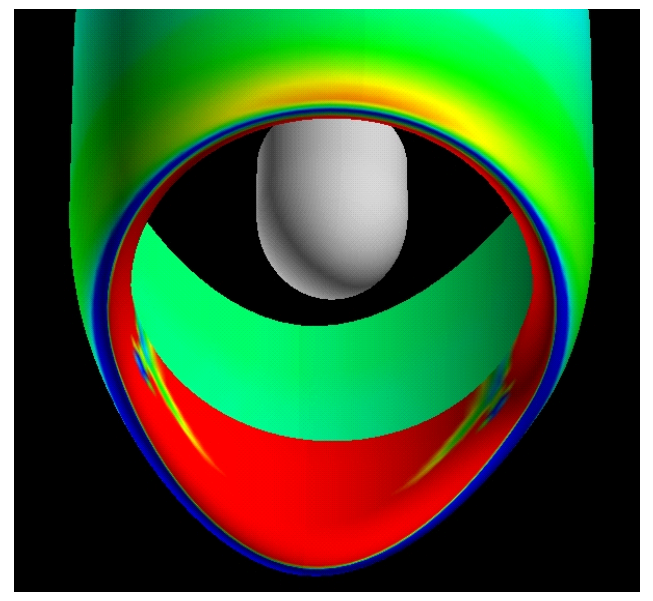

(c) $\mathrm{L}_{\mathrm{S}} / \mathrm{R}_{\mathrm{FF}}=0.625 ; \alpha=27.0^{\circ}$

Figure 16. Surface skin friction coefficient for scarf inlets for $\beta=67.5^{\circ} . C R=1.25$. Angle-of-attack is just beyond the separation value. $M_{0}, 0.25 ; M_{D E}, 0.60$. 


\section{Final Comments}

Figure 17 is a summary figure that provides an overall perspective on the results of this study. The figure shows three curves corresponding to three values of $\beta ; 180^{\circ}, 135^{\circ}$ and $90^{\circ}$. Each of the curves is taken from previous figures and represents those values of contraction ratio and lower lip extension for which the separation angle-ofattack is $30^{\circ}$. Shown on each of the curves is the inlet volume, V. The point of the figure is the following: If a subsonic inlet is to be designed to operated separation free up to an angle-of-attack of $30^{\circ}$, then any combination of $\beta, C R$ and $L_{S} / R_{D E}$ on the three curves will provide that capability. Note that the "Static Upper Lip Separation" bound is shown on the figure and limits the acceptable range of these three design parameters. (The "Cruise Upper Lip Separation" bound is not shown in the figure because it's to the right of the "Static" limit and thus is of no consequence.) Now the question becomes: What's the best inlet design to provide that angle-of-attack capability? Well, clearly if inlet volume (and hence inlet weight) is the figure of merit, then the figure shows that a scarf inlet having a $\beta$ of $90^{\circ}$ with a $C R$ of about 1.21 and an $\mathrm{L}_{\mathrm{S}} / \mathrm{R}_{\mathrm{DE}}$ of about 0.25 will provide that capability with the minimal inlet volume.

Note from figure 17 that the three curves are converging as they ascend to the left. They should do that, and where they cross the ordinate is at the value of CR that would be necessary for an axisymmetric inlet to provide the $30^{\circ}$ angle-of-attack capability. Extrapolating the curves that way indicates that value of CR is about 1.36. The volume for that particular inlet design is 1.98 . That value is $15 \%$ higher than the volume for the previously discussed $\beta=90^{\circ}$ scarf inlet that provides the same angle-of-attack capability.

To wrap up this discussion: If a "traditional" axisymmetric subsonic inlet is required to provide a $30^{\circ}$ angle-ofattack capability at takeoff, then its contraction ratio needs to be 1.36 and its volume will be 1.98 . That same capability can be provided by a scarf inlet having a $\beta=180^{\circ}$, a contraction ratio of 1.3 and a lower lip extension of 0.20 . That scarf inlet will have a volume of about 1.88 which is $5 \%$ less than the axisymmetric design. That same capability can also be provided by a scarf inlet having a $\beta=90^{\circ}$, a contraction ratio of 1.21 and a lower lip extension of 0.25 . That scarf inlet will have a volume of about 1.68 which is $15 \%$ less than the axisymmetric design. Clearly there is an inlet volume (and weight) advantage associated with reducing $\beta$ while meeting a specified separation angle-of-attack capability.

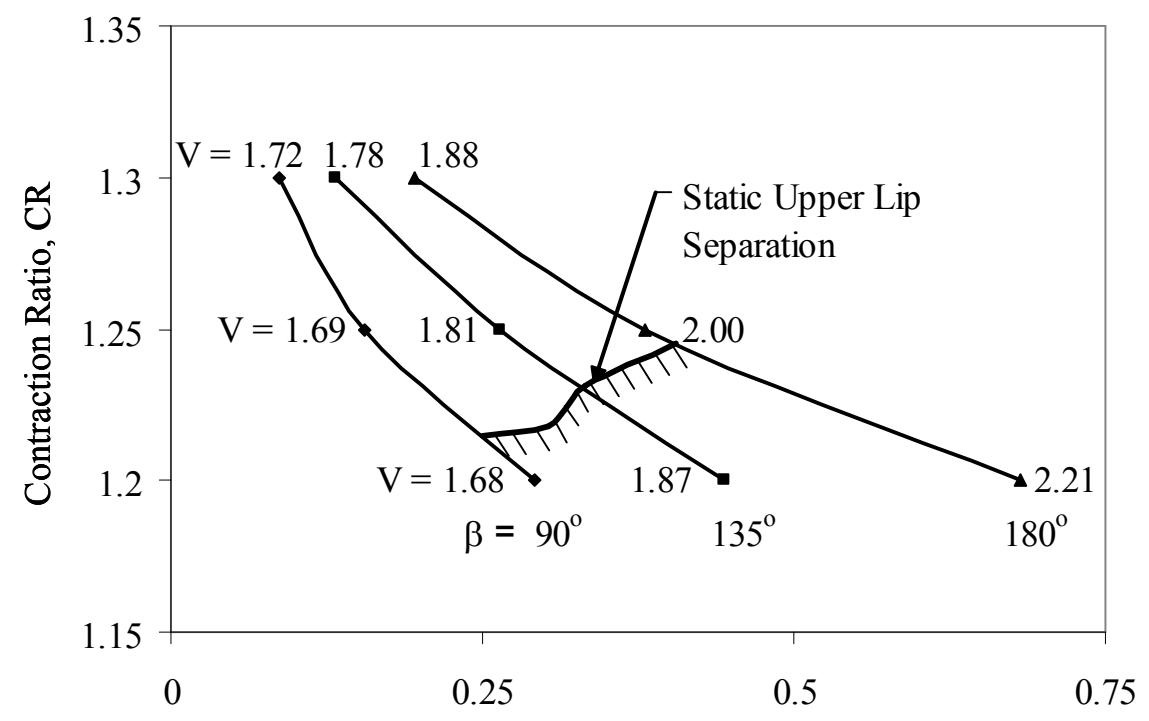

Lower Lip Extension, $\mathrm{L}_{\mathrm{S}} / \mathrm{R}_{\mathrm{DE}}$

Figure 17. Summary of effect of $\beta$ on scarf inlet performance at $\alpha$ SEP $=30^{\circ}$. $\mathrm{M}_{\mathbf{0}}, \mathbf{0 . 2 5} ; \mathrm{M}_{\mathrm{DE}}, \mathbf{0 . 6 0}$. 


\section{Summary of Results}

A computational study has been conducted to assess the aerodynamic performance of subsonic scarf inlet designs. Results from the study are summarized as follows:

1. Extending the lower lip of a subsonic inlet to form a scarf inlet, increases $\alpha_{\operatorname{SEP}}$ for a given lip thickness (contraction ratio) at takeoff Mach numbers. Thus, there is a tradeoff that can be made between lip thickness and lower lip extension in order to meet a given inlet angle-of-attack requirement. As this tradeoff is made, inlet volume also changes and must be considered in the trade.

2. Static and cruise inlet operation impose limits on the tradeoff that can be made between lip thickness and lower lip extension. Proper tailoring of the thickness of the upper portion of the inlet lip may lead to an easing of these limits.

3. Reducing the circumferential angle over which the lower lip was extended from $180^{\circ}$ to $67.5^{\circ}$ leads to scarf inlets of lower volume (weight) that meet the design requirements of a given angle-of-attack capability while maintaining attached upper lip flow at static and cruise conditions.

4. As an example, for an angle-of-attack requirement of $30^{\circ}$ at takeoff, the results are as follows:

\begin{tabular}{|c|c|c|}
\hline$\underline{\beta}$ & $\underline{\text { Volume }}$ & \% Reduction \\
\hline $0^{\circ}(\mathrm{Axi})$ & 1.98 & - \\
\hline $180^{\circ}$ & 1.88 & 5 \\
\hline $90^{\circ}$ & 1.68 & 15 \\
\hline
\end{tabular}

5. There is a clear inlet volume reduction associated with reducing $\beta$ for scarf inlet designs to achieve a given takeoff angle-of-attack capability. However, addition studies are need to assess the impact of other possible limiting operating conditions such as crosswind and engine out climb.

\section{Future Work}

A fair amount of additional work needs to be completed as part of this research effort. In particular:

1. Other operating conditions need to be explored including crosswind and engine out climb. Operation at these other conditions will impose additional operating bounds on the design curves.

2. The effect of Reynolds number (scale) needs to be evaluated. Thus far the computations have been done with an inlet diffuser exit diameter of one foot. Calculations for full size inlets need to be performed.

3. Other aspects of three-dimensionality need to be considered. For example, circumferential variation in lip thickness (internal and external).

4. The effect of the asymmetric capture streamline on inlet forces (lift and drag) needs to be evaluated.

5. Other sets of inlet design groundrules and other ranges of design parameters need to be explored. For example, lower contraction ratios and higher cruise Mach numbers.

6. And finally, it would be extremely valuable to conduct a series of experiments with carefully fabricated models to provide additional validation data. 


\section{References}

1. Abbott, J.M., Dietrich, D.A., “Aerodynamic and Directional Acoustic Performance of a Scoop Inlet”, NASA TP-1028, September, 1977.

2. Abbott, J.M., “Aerodynamic Performance of Scarf Inlets”, AIAA Paper 79-0380, January, 1979.

3. Abbott, J.M., and Slater, John W., "Computational Study of the Aerodynamic Performance of ThreeDimensional Subsonic Inlets”, AIAA Paper 2001-3886, July 2001.

4. Bush, R.H., Power G.D., and Towne, C.E., "WIND: The Production Flow Solver of the NPARC Alliance", AIAA Paper 0935, January 1998.

5. WIND Code web site, http://www.grc.nasa.gov/www/winddocs 